\title{
Proteomic Analysis of the Hydrogen and Carbon Monoxide Metabolism of Methanothermobacter marburgensis
}

\author{
Martijn Diender ${ }^{1 *}$, Ricardo Pereira ${ }^{1}$, Hans J. C. T. Wessels ${ }^{2}$, Alfons J. M. Stams ${ }^{1,3}$ and \\ Diana Z. Sousa ${ }^{1}$ \\ ${ }^{1}$ Laboratory of Microbiology, Wageningen University, Wageningen, Netherlands, ${ }^{2}$ Department of Laboratory Medicine, \\ Radboud University Medical Center, Nijmegen, Netherlands, ${ }^{3}$ Centre of Biological Engineering, University of Minho, Braga, \\ Portugal
}

Hydrogenotrophic methanogenic archaea are efficient $\mathrm{H}_{2}$ utilizers, but only a few are known to be able to utilize CO. Methanothermobacter thermoautotrophicus is one of the hydrogenotrophic methanogens able to grow on CO, albeit about 100 times slower than on $\mathrm{H}_{2}+\mathrm{CO}_{2}$. In this study, we show that the hydrogenotrophic methanogen Methanothermobacter marburgensis, is able to perform methanogenic growth on $\mathrm{H}_{2} / \mathrm{CO}_{2} / \mathrm{CO}$ and on $\mathrm{CO}$ as a sole substrate. To gain further insight in its carboxydotrophic metabolism, the proteome of $M$. marburgensis, grown on $\mathrm{H}_{2} / \mathrm{CO}_{2}$ and $\mathrm{H}_{2} / \mathrm{CO}_{2} / \mathrm{CO}$, was analyzed. Cultures grown with $\mathrm{H}_{2} / \mathrm{CO}_{2} / \mathrm{CO}$ showed relative higher abundance of enzymes involved in the reductive acetyl-CoA pathway and proteins involved in redox metabolism. The data suggest that the strong reducing capacity of $\mathrm{CO}$ negatively affects hydrogenotrophic methanogenesis, making growth on CO as a sole substrate difficult for this type of methanogens. $M$. marburgensis appears to partly deal with this by up-regulating co-factor regenerating reactions and activating additional pathways allowing for formation of other products, like acetate.

Keywords: syngas, methanogenesis, CODH, reductive acetyl-CoA pathway, Methanothermobacter thermoautotrophicus

\section{INTRODUCTION}

Methanogenesis from hydrogen, acetate, methanol, or methanethiols is a relatively well-studied process (Thauer et al., 2008). In 1931, CO was shown to potentially act as a substrate for methanogens in mixed cultures (Fischer et al., 1931), but knowledge of carboxydotrophic methanogenesis is still rather limited. Gaining insight in CO-driven methanogenesis is not only of interest from a fundamental point of view, but also from an applied scope. The rapid development of syngas technology makes it cheaper to convert any carbon rich source into a gaseous mixture, consisting mainly of $\mathrm{CO}, \mathrm{H}_{2}$, and $\mathrm{CO}_{2}$ (syngas). Syngas-driven carboxydotrophic methanogenesis can be considered as an alternative to biogas production via anaerobic digestion. About 10-25\% of the biomass consists of lignin, which is difficult to degrade biologically and can even prevent degradation of easily degradable biopolymers such as hemicellulose (Daniell et al., 2012; Jönsson and Martín, 2016). Additionally, biomass-derived biogas contains a fraction of $25-45 \% \mathrm{CO}_{2}$ (De Mes et al., 2003) and needs to be subsequently upgraded to bio-methane before injection in the gas grid is possible. Via the syngas route a higher substrate conversion yield can be achieved, and by increasing the $\mathrm{H}_{2}$ content of the gas substrate $\mathrm{CO}_{2}$-free end product can be obtained in one process step. 
Carbon monoxide appears to be a difficult substrate for methanogens, and only three methanogens have been shown to utilize it for growth: Methanothermobacter thermoautotrophicus (Daniels et al., 1977), Methanosarcina barkeri (O’Brien et al., 1984; Bott et al., 1986), and Methanosarcina acetivorans (Rother and Metcalf, 2004). Carboxydotrophic growth of M. thermoautotrophicus is possible with $\mathrm{CO}$ as a sole carbon source up to pressures of $50 \mathrm{kPa}$. Doubling times reported for CO-grown $M$. thermoautotrophicus are about $200 \mathrm{~h}$, which is about a 100 times slower than with $\mathrm{H}_{2} / \mathrm{CO}_{2}$ (Daniels et al., 1977). M. barkeri was observed to utilize $100 \mathrm{kPa}$ $\mathrm{CO}$, but also at a relatively slow doubling time (about $65 \mathrm{~h}$ ) compared to growth on other substrates (O'Brien et al., 1984). Methanosarcina acetivorans can withstand higher CO partial pressures $(>150 \mathrm{kPa})$ and grows on $\mathrm{CO}$ with a doubling time of about $20 \mathrm{~h}$. However, it shifts its methanogenic metabolism toward formation of acetate and formate with increasing CO pressures (Rother and Metcalf, 2004). Detailed research has been performed on the $\mathrm{CO}$ metabolism of $M$. acetivorans (Rother and Metcalf, 2004; Lessner et al., 2006; Rother et al., 2007; Matschiavelli et al., 2012), providing more insight in the enzymes involved in carboxydotrophic metabolism of this aceticlastic methanogen. Currently, M. thermoautotrophicus is the only hydrogenotrophic methanogen known that can grow on $\mathrm{CO}$ as a substrate, and there is limited knowledge on the carboxydotrophic metabolism of hydrogenotrophic methanogens in general. Carboxydotrophic methanogenesis is expected to be operated in a similar way as hydrogenotrophic metabolism (Daniels et al., 1977; Diender et al., 2015). Electrons derived from the oxidation of $\mathrm{CO}$ or $\mathrm{H}_{2}$ are used to reduce $\mathrm{CO}_{2}$ to methyl-tetrahydromethanopterin (methyl- $\mathrm{H}_{4} \mathrm{MPT}$ ). This keyintermediate can subsequently be converted into either methane, for energy generation, or assimilated via acetyl-CoA, for biomass production.

In this study, we aimed to assess the CO-metabolism of Methanothermobacter marburgensis. M. marburgensis has a highly similar CODH sequence to that of $M$. thermoautotrophicus (93\% identity). Additionally, it was shown that the methylcoenzyme $M$ reductase (MCR) of $M$. marburgensis was activated 15 times faster by $\mathrm{CO}$ than by $\mathrm{H}_{2}$ (Zhou et al., 2013). Here we show that $M$. marburgensis can grow methanogenically on $\mathrm{CO}$ and we assessed its carboxydotrophic metabolism via physiological analysis and proteomics. Additionally, we evaluated the limitations of this type of metabolism, which is theorized to be related to hydrogenase inhibition or redox-stress (Diender et al., 2015).

\section{MATERIALS AND METHODS}

\section{Strains and Cultivation}

Strains M. thermoautotrophicus (DSM 1053) and M. marburgensis (DSM 2133) were obtained from the German Collection of Microorganisms and Cell Cultures (DSMZ; Braunschweig, Germany). Strains were initially cultivated at $65^{\circ} \mathrm{C}$ on recommended Methanobacterium medium (DSM-119) using anaerobic cultivation procedures. After growth was confirmed, the strains were adapted to growth in a carbonate-phosphate buffered medium with the following composition: $0.4 \mathrm{~g} / \mathrm{l}$ $\mathrm{KH}_{2} \mathrm{PO}_{4}, 0.53 \mathrm{~g} / \mathrm{l} \mathrm{K}_{2} \mathrm{HPO}_{2}{ }^{*} 2 \mathrm{H}_{2} \mathrm{O}, 0.3 \mathrm{~g} / \mathrm{l} \mathrm{NH}{ }_{4} \mathrm{Cl}, 0.3 \mathrm{~g} / \mathrm{l} \mathrm{NaCl}$, $0.1 \mathrm{~g} / 1 \mathrm{MgCl}_{2} * 6 \mathrm{H}_{2} \mathrm{O}, 0.5 \mathrm{~g} / \mathrm{l}$ yeast extract and $0.5 \mathrm{mg} / \mathrm{l}$ resazurin. Medium was supplemented, per liter, with $61.8 \mu \mathrm{g} \mathrm{H}_{3} \mathrm{BO}_{3}$, $61.25 \mu \mathrm{g} \mathrm{MnCl}_{2}, 943.5 \mu \mathrm{g} \mathrm{FeCl}_{2}, 64.5 \mu \mathrm{g} \mathrm{CoCl}, 12.86 \mu \mathrm{g} \mathrm{NiCl}_{2}$, $67.7 \mu \mathrm{g} \mathrm{ZnCl}_{2}, 13.35 \mu \mathrm{g} \mathrm{CuCl}_{2}, 17.3 \mu \mathrm{g} \mathrm{Na} \mathrm{NeO}_{3}, 29.4 \mu \mathrm{g}$ $\mathrm{Na}_{2} \mathrm{WO}_{4}$, and $20.5 \mu \mathrm{g} \mathrm{Na} \mathrm{MoO}_{4}$. Medium was prepared, boiled and cooled under a continuous nitrogen flow. Bottles $(120 \mathrm{ml}$ total volume, $50 \mathrm{ml}$ liquid) were filled with medium and instantly capped with rubber stopper and aluminum cap. The gas phase was exchanged with either $80: 20 \mathrm{~N}_{2} / \mathrm{CO}_{2}$ or $80: 20 \mathrm{H}_{2} / \mathrm{CO}_{2}$, resulting in a final pressure of $170 \mathrm{kPa}$. When necessary, the headspace was further fine-tuned by addition of CO, keeping final pressure at $170 \mathrm{kPa}$. The bottles were autoclaved and stored at room temperature till further use. Before inoculation medium was supplied with the following volumes of stock solutions: $1 \%$ of $11 \mathrm{~g} / \mathrm{l} \mathrm{CaCl}_{2} * 2 \mathrm{H}_{2} \mathrm{O}, 1 \%$ of a vitamin solution containing per liter: biotin $20 \mathrm{mg}$, nicotinamide $200 \mathrm{mg}$, p-aminobenzoic acid $100 \mathrm{mg}$, thiamin $200 \mathrm{mg}$, panthotenic acid $100 \mathrm{mg}$, pyridoxamine $500 \mathrm{mg}$, cyanocobalamin $100 \mathrm{mg}$, riboflavin $100 \mathrm{mg}$. The medium was reduced by introducing a $5 \%$ volume of a stock solution containing $4.8 \mathrm{~g} / 1 \mathrm{Na}_{2} \mathrm{~S} * x \mathrm{H}_{2} \mathrm{O}$ $(x=7-9)$ and $80 \mathrm{~g} / \mathrm{NaHCO}_{3}$. Unless stated otherwise, bottles were inoculated with an exponentially growing culture in a 1:50 ratio $(\mathrm{v} / \mathrm{v})$.

\section{Analytical Procedures}

Headspace composition was determined by gas chromatography using a GC-2014 (Shimadzu, Kyoto, Japan) equipped with a thermal conductivity detector. $\mathrm{H}_{2}, \mathrm{CH}_{4}$, and $\mathrm{CO}$ were measured with a Molsieve 13X column, $2 \mathrm{~m}$ long and an inner diameter of $3 \mathrm{~mm}$. Argon was used as carrier gas at a flow rate of $50 \mathrm{ml} / \mathrm{min}$. Injector, column and detector temperatures were set to 80,60 , and $130^{\circ} \mathrm{C}$, respectively. $\mathrm{CO}_{2}$ was measured separately in a CP Poraplot column of $25 \mathrm{~m} \times 0.53 \mathrm{~mm}$, with a stationary phase film thickness of $20 \mu \mathrm{m}$, employing helium as carrier gas at a flow rate of $15 \mathrm{ml} / \mathrm{min}$. Injector, column and detector temperatures were set to 60,34 , and $130^{\circ} \mathrm{C}$, respectively. The detection limits for $\mathrm{H}_{2}, \mathrm{CO}, \mathrm{CO}_{2}$, and $\mathrm{CH}_{4}$ were 20, 250, 20, and $80 \mathrm{~Pa}$, respectively.

Liquid phase composition was analyzed via high pressure liquid chromatography equipped with a MetaCarb $67 \mathrm{H}$ column (Agilent Technologies, Santa Clara, CA, USA). The column was operated at a temperature of $45^{\circ} \mathrm{C}$ with a flow rate of $0.8 \mathrm{ml} / \mathrm{min}$ using $0.01 \mathrm{~N} \mathrm{H}_{2} \mathrm{SO}_{4}$ as eluent. Detection of acetate was done using an RI and UV detector. Concentrations of $0.5 \mathrm{mM}$ could be accurately determined and lower levels are referred to as trace amounts.

\section{Cell Free Extract Preparation and Measuring CO-Oxidation Activity}

Cells of $M$. marburgensis were grown on either 80:20 $\mathrm{H}_{2} / \mathrm{CO}_{2}$ or 60:20:20 $\mathrm{H}_{2} / \mathrm{CO}_{2} / \mathrm{CO}$. Biological triplicates were prepared for each condition. Cells were harvested at end log-phase in an anaerobic tent, where the broth was centrifuged at $13000 \times g$ for 
$10 \mathrm{~min}$. Supernatant was discarded and the pellets were dissolved in $1 \mathrm{ml} 50 \mathrm{mM}$ Tris- $\mathrm{HCl}, \mathrm{pH}$ 8. Cells were disrupted using a VC40 sonicator (Sonics materials, Newtown, CT, USA) using five cycles of $30 \mathrm{~s}$ sonication, at a power input of $20 \mathrm{~W}$, followed by $30 \mathrm{~s}$ rest at $0^{\circ} \mathrm{C}$. Cell free extract (CFE) was put in $5 \mathrm{ml}$ glass vials and capped with rubber stoppers inside the anaerobic tent. Subsequently, the headspace of these vials was exchanged to 1.5 bar $\mathrm{N}_{2}$ to remove traces of $\mathrm{H}_{2}$.

CO-oxidation activity of the CFE was determined as follows: glass cuvettes ( $2 \mathrm{ml}$ total volume) were closed with a rubber stopper and flushed three times by using $5 \mathrm{ml} \mathrm{N}_{2}$ or CO. Subsequently, $1 \mathrm{ml}$ assay buffer (50 mM MOPS, pH 7, $20 \mathrm{mM}$ methyl viologen (MV) and $2 \mathrm{mM} \mathrm{DTT}$ ) was added to the cuvette and reduced with $1 \mu \mathrm{l}$ of $100 \mathrm{mM}$ dithionite. The cuvette was put into a pre-heated U-2010 spectrophotometer (Hitachi, Tokyo, Japan) and was left to heat up to $60^{\circ} \mathrm{C}$. Absorption of MV was measured at $578 \mathrm{~nm}$. The initial extinction was set to a value between 0.2 and 0.6. After obtaining a stable baseline, 50 or $25 \mu \mathrm{l}$ CFE was added to the cuvette, initiating the reaction. Each separate biological sample was assessed for CO-oxidizing activity and endogenous activity (using $\mathrm{N}_{2}$ instead of $\mathrm{CO}$ ). The initial activity of CO-oxidation after CFE addition was taken, and corrected for the initial slope of the endogenous activity. In order to confirm that $\mathrm{CO}$ was the electron donor, cuvettes were prepared with $\mathrm{N}_{2}$ headspace and CFE was added. After seizure of endogenous activity $0.3 \mathrm{ml} \mathrm{CO}$ was added to the sample as initiation trigger. Each biological sample was at least analyzed in duplicate using either 50 or $25 \mu \mathrm{l} \mathrm{CFE}$. An extinction coefficient $9.7 \mathrm{mM}^{-1} \mathrm{~cm}^{-1}$ (Bonam and Ludden, 1987) was used for MV at $578 \mathrm{~nm}$. Protein concentration in the CFE was determined by using Roti-Nanoquant protein quantitation assay (CarlRoth, Karlsruhe, Germany), according to manufacturer instructions.

\section{Sample Preparation for Proteomics}

Duplicate cultures of $M$. marburgensis grown in two conditions, 80:20 $\mathrm{H}_{2} / \mathrm{CO}_{2}$ and 60:20:20 $\mathrm{H}_{2} / \mathrm{CO}_{2} / \mathrm{CO}$, were harvested in late exponential phase by centrifugation (cultivation was performed in 11 anaerobic bottles containing $500 \mathrm{ml}$ medium). Prior to centrifugation cultures were quickly cooled down on ice and kept at $4^{\circ} \mathrm{C}$ for $30 \mathrm{~min}$ to decrease cell activity. Cell pellets were resuspended in TE buffer (10 mM Tris-Cl, pH 7.5; 1 mM EDTA) containing $1 \mathrm{mM}$ phenylmethanesulfonyl fluoride, and passed through a French pressure cell operated at $138 \mathrm{MPa}$. Proteins were stabilized by addition of $8 \mathrm{M}$ of urea in a proportion of 1:1 and samples were concentrated using a $3.5 \mathrm{kDa}$ MWCO filter. Final protein concentration in samples obtained for LCMS/MS analysis were assessed using Qubit ${ }^{\circledR}$ Protein Assay Kit in a Qubit ${ }^{\circledR} 2.0$ Fluorometer (Life technologies). Samples were subjected to in-solution tryptic digestion as described elsewhere (Wessels et al., 2010).

\section{LC-MS/MS Data Acquisition}

Protein samples obtained from the two sets of biological duplicates were analyzed in duplicate using C18 reversed phase liquid chromatography with online tandem mass spectrometry (LC-MS/MS). Measurements were performed using a nanoflow ultra-high pressure liquid chromatograph (nano-Advance; Bruker Daltonics) coupled online to an orthogonal quadrupole time-of-flight mass spectrometer (maXis 4G ETD, otofControl v3.4 build 14; Bruker Daltonics) via an axial desolvation vacuum assisted electrospray ionization source (Captive sprayer; Bruker Daltonics). Five microliters of tryptic digest were loaded onto the trapping column (Acclaim PepMap 100, $75 \mu \mathrm{m} \times 2 \mathrm{~cm}$, nanoViper, $3 \mu \mathrm{m} 100 \AA \mathrm{C} 18$ particles; Thermo Scientific) using $0.1 \% \mathrm{FA}$ at a flow rate of $9000 \mathrm{nl} / \mathrm{min}$ for $3 \mathrm{~min}$ at room temperature. Next, peptides were separated on a C18 reversed phase $15 \mathrm{~cm}$ length $\times 75 \mu \mathrm{m}$ internal diameter analytical column (Acclaim PepMap RSLC, $75 \mu \mathrm{m} \times 15 \mathrm{~cm}$, nanoViper, $2 \mu \mathrm{m}$ $100 \AA$ C18 particles; Thermo scientific) at $40^{\circ} \mathrm{C}$ using a linear gradient of $3-35 \%$ ACN $0.1 \% \mathrm{FA}$ in $120 \mathrm{~min}$ at a flow rate of $600 \mathrm{nl} / \mathrm{min}$. The mass spectrometer was operated in positive ion mode and was tuned for optimal ion transmission in the range of $\mathrm{m} / \mathrm{z} 300-1400$. Electrospray ionization conditions were $3 \mathrm{l} / \mathrm{min} 180^{\circ} \mathrm{C} \mathrm{N}_{2}$ drying gas, $1400 \mathrm{~V}$ capillary voltage and 0.4 Bar $\mathrm{N}_{2}$ for gas phase supercharging (nanobooster) using acetonitrile as dopant. Parameters for optimal ion transmission were funnel RF: $400 \mathrm{Vpp}$, multipole RF: $400 \mathrm{Vpp}$, quadrupole ion energy: $5.0 \mathrm{eV}$, quadrupole low mass: $300 \mathrm{~m} / \mathrm{z}$, collision cell energy: $9.0 \mathrm{eV}$, collision cell RF: $3500 \mathrm{Vpp}$, ion cooler transfer time: $64 \mu \mathrm{s}$, ion cooler RF: $250 \mathrm{Vpp}$, pre-pulse storage: $22 \mu \mathrm{s}$. Data dependent acquisition of MS/MS spectra (AutoMSn) was performed using a $3 \mathrm{~s}$ duty cycle at $2 \mathrm{~Hz}$ acquisition rate for full MS spectra and a variable number of MS/MS experiments at precursor intensity scaled spectra rate $(3 \mathrm{~Hz} \mathrm{MS} / \mathrm{MS}$ spectra rate at 2000 counts, $20 \mathrm{~Hz}$ MS/MS spectra rate @ 100.000 counts). Precursor ions within the range of $400-1400 \mathrm{~m} / \mathrm{z}$ with charge state $z=2+$ or higher (preferred charge state range of $z=2+$ to $z=4+$ ) were selected for MS/MS analysis with active exclusion enabled (excluded after one spectrum, released after $0.5 \mathrm{~min}$, reconsidered precursor if current intensity/previous intensity $\geq 4$, smart exclusion disabled). Spectra were saved as line spectra only and were calculated from profile spectra as the sum of intensities across a mass spectral peak (five counts absolute threshold, peak summation width seven points).

\section{Proteomics Analysis}

Protein identification and relative quantitation was performed using the MaxQuant software (v.1.5.0.0; Cox and Mann, 2008) using the build-in Andromeda database search algorithm. Extracted MS/MS spectra were searched against the SWISS-PROT $M$. marburgensis protein sequence database. Amino acid sequences of known contaminant proteins (e.g., skin and hair proteins, Trypsin, LysC) were added to the database. The following settings were used for peptide and protein identification: carbamidomethyl (Cys) as fixed modification, oxidation (Met), and deamidation (NQ) as variable modifications, predefined MS and MS/MS settings for TOF instruments, minimal peptide length six amino acids and a maximum allowed false discovery rate of $1 \%$ at both the peptide and protein level. Label free quantitation (LFQ) was performed with the match between runs and re-quantify options using at least 2 razor + unique peptides. Retention 
time alignment was performed with a time alignment window of $20 \mathrm{~min}$ and a retention time match window of $0.5 \mathrm{~min}$. Label-free quantitation (LFQ) values were used for subsequent data analysis. Proteins quantified in at least three out of four measurements for either growth condition were analyzed by student's $t$-tests to identify differentially expressed proteins with $p<0.05$. The mass spectrometry proteomics data have been deposited to the ProteomeXchange Consortium via the PRIDE (Vizcaíno et al., 2016) partner repository with the dataset identifier PXD003661.

\section{RESULTS}

\section{Carboxydotrophic Growth of $M$. thermoautotrophicus and M. marburgensis}

Both, M. thermoautotrophicus and $M$. marburgensis were capable of growing methanogenically on $\mathrm{H}_{2} / \mathrm{CO}_{2} / \mathrm{CO}$ or $\mathrm{CO}$ as a sole substrate. When assessing the production profiles on $\mathrm{H}_{2} / \mathrm{CO}_{2} / \mathrm{CO}$, it appears that both strains co-utilize $\mathrm{H}_{2}$ and $\mathrm{CO}$ (Figure 1). For both strains $\mathrm{H}_{2}$ utilization becomes slower with exposure to higher $\mathrm{CO}$ pressures. The maximal $\mathrm{H}_{2}$ consumption rate of $M$. marburgensis dropped from 1.3 to $0.43 \mathrm{mmol} / \mathrm{l}_{\mathrm{liquid}} / \mathrm{h}$ when increasing the $\mathrm{CO}$ pressure from 0 to $70 \mathrm{kPa}$. Similarly M. thermoautotrophicus decreased its maximal $\mathrm{H}_{2}$ consumption rate from 0.55 to $0.19 \mathrm{mmol} / \mathrm{l}_{\text {liquid }} / \mathrm{h}$ when increasing the $\mathrm{CO}$ pressure from 0 to $70 \mathrm{kPa}$. M. marburgensis could be grown on $\mathrm{CO}$ as a sole substrate up to $50 \mathrm{kPa}$ (data not shown), which is similar to the value found for $M$. thermoautotrophicus (Daniels et al., 1977).

M. marburgensis appears to utilize carbon monoxide more easily as it depletes $34 \mathrm{kPa}$ CO within $120 \mathrm{~h}$, while M. thermoautotrophicus uses this substrate significantly slower (Figure 1). This suggests that $M$. marburgensis can be better adapted to carboxydotrophic growth than M. thermoautotrophicus. It was attempted to adapt both strains to cultivation on purely $\mathrm{CO}$ by repeatedly transferring them in presence of solely $\mathrm{CO}$ as electron donor. The initial lag phase of $M$. marburgensis growing solely on $34 \mathrm{kPa} \mathrm{CO}$ was $\sim 500 \mathrm{~h}$, but in the two subsequent transfers the lag phase for $\mathrm{CO}$ conversion decreased to $\sim 100 \mathrm{~h}$ (Figure 2 ). CO consumption and methane production rates between these transfers did not change significantly (Figure 2). Cultures transferred back to $\mathrm{H}_{2} / \mathrm{CO}_{2}$ quickly lost this adaptation to $\mathrm{CO}$ and showed again a longer lag phase when incubated with $\mathrm{CO}$ alone. Nevertheless, a re-adaptation of these cultures to $\mathrm{CO}$ was possible. Growth of $M$. thermoautotrophicus on $\mathrm{H}_{2} / \mathrm{CO}_{2} / \mathrm{CO}$ or $\mathrm{CO}$ as the sole substrate could not be improved via subsequent transfers, nor could the lag phase be decreased. Due to this inefficient growth of $M$. thermoautotrophicus in presence of $\mathrm{CO}$ it was decided to perform further analysis and proteomics solely with M. marburgensis.

In all cultures of $M$. marburgensis growing on $\mathrm{CO}$ as a sole substrate, $\mathrm{H}_{2}$ is observed to accumulate in the headspace before the onset of methanogenesis (Figure 2). Upon initiation of carboxydotrophic methanogenesis, $\mathrm{H}_{2}$ is co-utilized. At the end of cultivation, not all the $\mathrm{CO}$ is converted to methane as approximately $1 \mathrm{~mol}$ methane is formed per $6 \mathrm{~mol} \mathrm{CO}$ consumed (Figure 2), suggesting formation of other products. Acetate formation was observed in incubations of $M$. marburgensis grown in presence of $\mathrm{CO}$, which ranged from 2 to $4 \mathrm{mM}$ at the end of cultivation.

Assessing the $M$. marburgensis $\mathrm{CO}$ oxidizing activity in the CFE of $\mathrm{H}_{2} / \mathrm{CO}_{2} / \mathrm{CO}$ grown cells resulted in a specific $\mathrm{MV}$

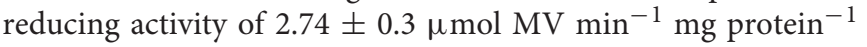
after correction for endogenous activity. $\mathrm{H}_{2} / \mathrm{CO}_{2}$ grown cells showed a specific $\mathrm{MV}$ reducing activity of $2.06 \pm 0.13 \mu \mathrm{mol} \mathrm{MV} \mathrm{m^{-1 }} \mathrm{mg}$ protein $^{-1}$ after correction for endogenous activity, which is about 1.3 times lower than in the condition with $\mathrm{CO}$. Additionally, the CFE of $\mathrm{H}_{2} / \mathrm{CO}_{2}$ grown cells showed no endogenous activity, while cells grown on $\mathrm{H}_{2} / \mathrm{CO}_{2} / \mathrm{CO}$ showed an average initial endogenous activity of $0.6 \mu \mathrm{mol} \mathrm{MV} \mathrm{\operatorname {min } ^ { - 1 } \mathrm { mg } \text { protein }}{ }^{-1}$. This endogenous activity decayed over time, completely seizing after $\sim 150$ s. Addition of $\mathrm{CO}$, after seizure of endogenous activity, resulted again in reduction of $\mathrm{MV}$ in all samples.

\section{Comparative Proteomics of M. marburgensis}

Comparative proteomic analysis was performed on M. marburgensis incubated with $80: 20 \mathrm{H}_{2} / \mathrm{CO}_{2}$ or $60: 20: 20$ $\mathrm{H}_{2} / \mathrm{CO}_{2} / \mathrm{CO}$. In the proteomics analysis 5845 peptides from 831 non-redundant proteins were identified [false discovery rate $(\mathrm{FDR}) \leq 1 \%$, average absolute mass error: $1.14 \pm 1.76 \mathrm{ppm})$ of which 590 proteins were quantified using at least two razor + unique peptides in $\geq 3$ measurements of either growth condition. Both the technical and biological reproducibility was very good based on median LFQ standard deviations of 6.9 and $18.4 \%$, respectively. In total, 203 proteins were found to be differentially abundant between the two growth conditions (student's $t$-test $p<0.05$, median LFQ standard deviation: $14.8 \%)$.

All the proteins required for hydrogenotrophic methanogenesis and the reductive acetyl-CoA pathway could be detected in both the $\mathrm{H}_{2} / \mathrm{CO}_{2}-$ and $\mathrm{H}_{2} / \mathrm{CO}_{2} / \mathrm{CO}$-grown cultures (Figure 3). In presence of $\mathrm{CO}$, several subunits of carbon monoxide dehydrogenase $(\mathrm{CODH})$ and acetyl-CoA synthase (ACS) were more abundant. Several enzymes in the methyl-branch of the acetyl-CoA pathway were found to be increased in abundance in the presence of CO (Table 1): mainly the formylmethanofuran dehydrogenase, methyl-coenzyme $\mathrm{M}$ reductase-I and the $\mathrm{F} 420$ dependent methylene- $\mathrm{H}_{4} \mathrm{MPT}$ dehydrogenase. Additionally, a higher abundance of the subunit $\mathrm{H}$ of the tetrahydromethanopterin $S$-methyltransferase was detected with $\mathrm{CO}$ as substrate. Other subunits of this complex were not significantly overproduced, and levels of subunit B and $\mathrm{G}$ were even lowered. Also, a predicted acetyl-CoA synthetase, theorized to be involved in acetate metabolism, was found to be more abundant.

Polyferredoxin, belonging to the energy conserving hydrogenase $(\mathrm{EcH})$, was more abundant in the presence of 


\section{A}
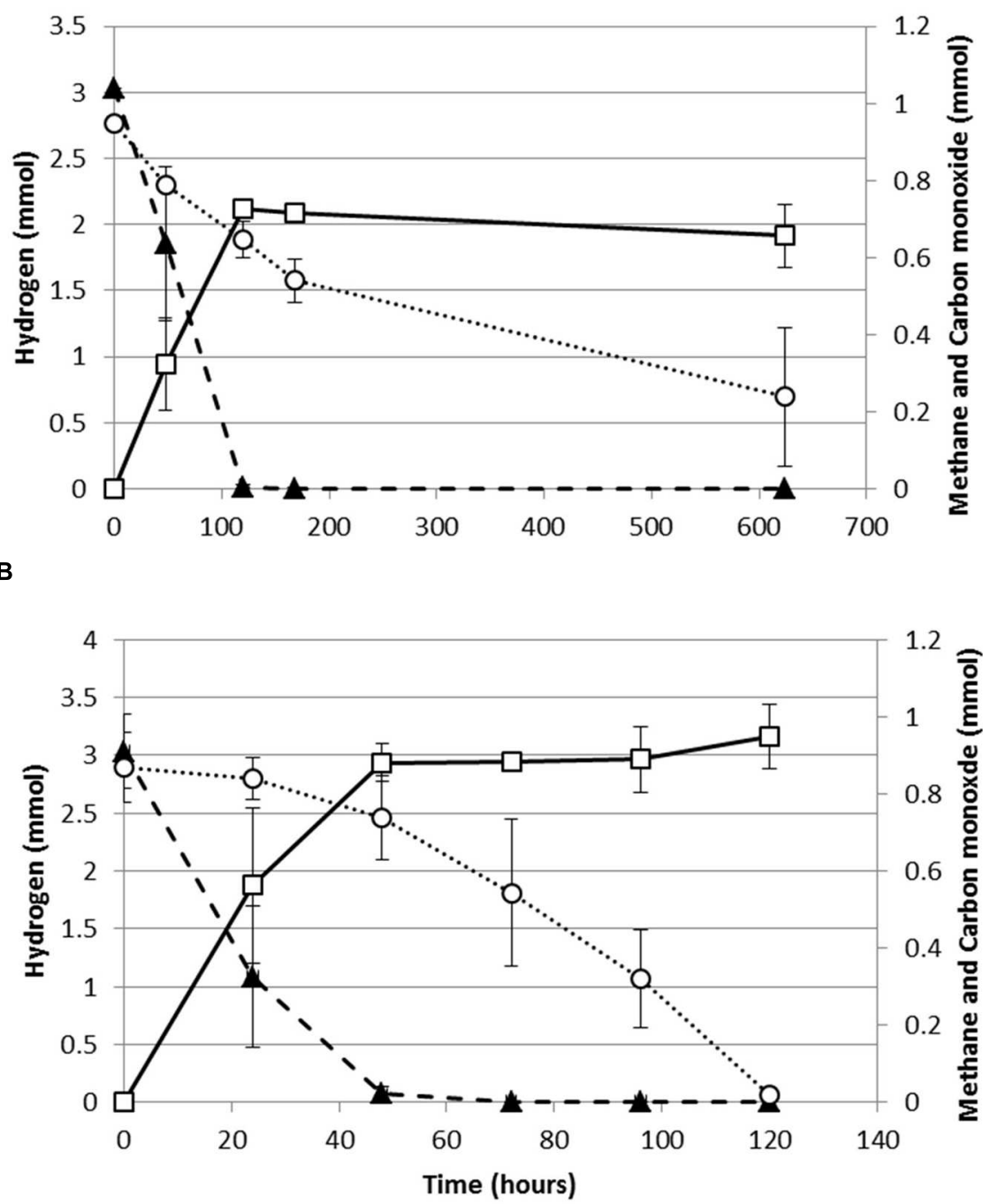

FIGURE 1 | Production profile of hydrogenotrophic methanogens growing on $\mathbf{H}_{2} / \mathbf{C O}_{2} / \mathbf{C O}$. (A) Production profile of $M$. thermoautotrophicus. (B) Production profile of M. marburgensis. Hydrogen: solid black triangles, Methane: open black squares, Carbon monoxide: open black circles. Gas is represented as total amount of mmol present in the bottle headspace. Error bars display maximal and minimal amounts over duplicate experiments.

$\mathrm{CO}$, but other subunits of this $\mathrm{EcH}$ were not clearly differentially present. Other hydrogenase related proteins, such as the HypE protein, involved in hydrogenase maturation, and subunits of the F420-reducing hydrogenase were also found to be more abundant in cultures grown with $\mathrm{CO}$ in the headspace. In presence of $\mathrm{CO}$, several proteins related to redox stress were found in higher numbers: F420 oxidase, superoxide dismutase, superoxide reductase, and F390 synthetase (Supplementary Table S1). In addition to redox stress proteins, a predicted universal stress protein was found to be more abundant. Also a decrease in $30 \mathrm{~S}$ and $50 \mathrm{~S}$ ribosomal proteins was observed in presence of CO. Tuning down of ribosomal RNA and ribosomal proteins, is often observed as a response to different types of stress in Escherichia coli (Wagner, 1994), but also in other microorganisms this is observed (Abee and Wouters, 1999; van de Guchte et al., 2002). The decrease in ribosomal proteins in M. marburgensis in presence of CO could thus potentially be an additional indication of stress.

\section{DISCUSSION}

When growing on hydrogen, hydrogenotrophic methanogens generate methyl- $\mathrm{H}_{4} \mathrm{MPT}$ required in the final part of methanogenesis (Thauer et al., 2008). In addition, they can assimilate acetyl-CoA from methyl- $\mathrm{H}_{4} \mathrm{MPT}$ for biosynthetic purposes, by using the ACS. This requires $\mathrm{CODH}$ activity to reduce $\mathrm{CO}_{2}$ to $\mathrm{CO}$, which is subsequently condensed with methyl- $\mathrm{H}_{4} \mathrm{MPT}$ and $\mathrm{CoA}-\mathrm{SH}$ to form acetyl-CoA. For methanogens, the $\mathrm{CODH}$ complex is in almost all 

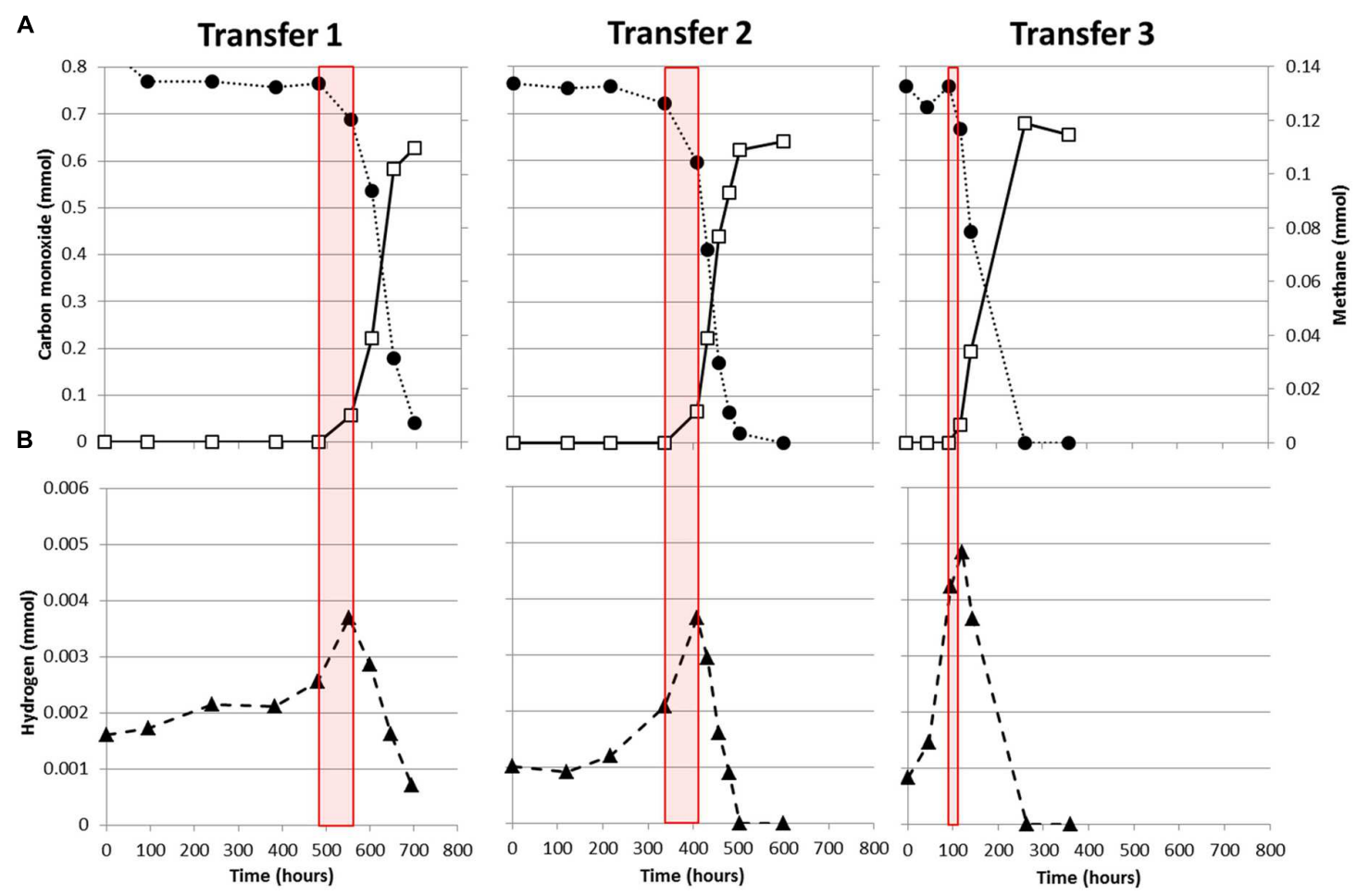

FIGURE 2 | Adaptation of $\boldsymbol{M}$. marburgensis to carboxydotrophic growth. (A) Consumption of CO (black solid circles) and production of methane (open squares). (B) $\mathrm{H}_{2}$ production and consumption profile during growth on $\mathrm{CO}$. Red planes indicate the timeframe where methanogenesis is initiated. Gas is represented as total amount of mmol present in the bottle headspace.

cases associated with an ACS complex (Techtmann et al., 2012), suggesting it mainly plays a role in the assimilatory metabolism.

\section{CODH/ACS Related Metabolism}

The slight, but significant, increase in CO-oxidation activity observed in the $\mathrm{CFE}$ of $\mathrm{H}_{2} / \mathrm{CO}_{2} / \mathrm{CO}$ grown cultures compared to the $\mathrm{CFE}$ of $\mathrm{H}_{2} / \mathrm{CO}_{2}$ grown cells suggests that more $\mathrm{CO}$ oxidizing enzymes are present. This is in accordance with the higher abundance of several CODH/ACS related proteins when M. marburgensis is grown in the presence of CO: the epsilon and gamma subunit of the main complex, the $\mathrm{CODH}$ maturation protein and a $\mathrm{CODH}$ related ferredoxin. Two $\mathrm{CODH}$-related operons can be found in the genome of $M$. marburgensis (cdh1 and cdh2; Liesegang et al., 2010). The cdh2 operon codes for all the five subunits of a CODH/ACS, a CODH-like maturation factor and a $\mathrm{CODH}$-related ferredoxin. Detection of the complete CODH/ACS complex under both of the tested conditions suggests that it is at least involved in assimilatory metabolism. Higher abundance of several CODH subunits, the $\mathrm{CODH}$ maturation factor and the $\mathrm{CODH}$-related ferredoxin in the $\mathrm{H}_{2} / \mathrm{CO}_{2} / \mathrm{CO}$ condition could indicate that the complex is also involved in $\mathrm{CO}$-oxidation, allowing transfer of electrons to other co-factors/proteins. Such an observation is also made in M. acetivorans of which the genome contains two CODH/ACS operons ( $c d h 1$ and $c d h 2)$. Higher abundance of these CODH/ACS complexes was observed during proteomic analysis comparing
$\mathrm{CO}$-grown to acetate- or methanol-grown cultures. This suggests an important role for the CODH/ACS complex in CO-oxidation (Lessner et al., 2006; Rother et al., 2007). It has been shown later on that both $\mathrm{Cdh}$ isoforms of $M$. acetivorans are functional $\mathrm{CODH} / \mathrm{ACS}$ complexes and that one isoform is sufficient for catabolic and anabolic functions (Matschiavelli et al., 2012). It is therefore likely that the CODH/ACS complex of M. marburgensis plays a main role in $\mathrm{CO}$-oxidation.

The $c d h 1$ operon of $M$. marburgensis contains the sequence of one pseudo annotated $\mathrm{CODH}$ alpha subunit and a sequence coding for a $\mathrm{HycB}$-like, ferredoxin-related, protein. The presence of the $\mathrm{HycB}$ gene next to the $\mathrm{CODH}$ sequence could indicate that this protein is involved in $\mathrm{CO}$-oxidation. However, its function remains unclear as this protein is not detected in the $\mathrm{H}_{2} / \mathrm{CO}_{2}$ nor the $\mathrm{H}_{2} / \mathrm{CO}_{2} / \mathrm{CO}$ condition. The genome of $M$. acetivorans contains three other $\mathrm{CODH}$ sequences in addition to the two $\mathrm{CODH} / \mathrm{ACS}$ operons: two monofunctional $\mathrm{CODH}$ related genes (cooS1F and cooS2) and one operon containing solely the alpha subunit of the CODH/ACS complex (cdhA3). Knockout studies showed that the two monofunctional CODHs are not essential for $\mathrm{CO}$ utilization, as $\mathrm{CO}$ was still utilized as a substrate in the knockout strains (Rother et al., 2007). These monofunctional CODHs were observed to have a function at elevated $\mathrm{CO}$ pressures as detoxification mechanism. The CdhA3 protein is suggested to play a role in $\mathrm{CO}$ sensing and is apparently not directly involved in CO oxidation (Matschiavelli et al., 2012). The Cdh1 of $M$. marburgensis was not detected in the conditions 


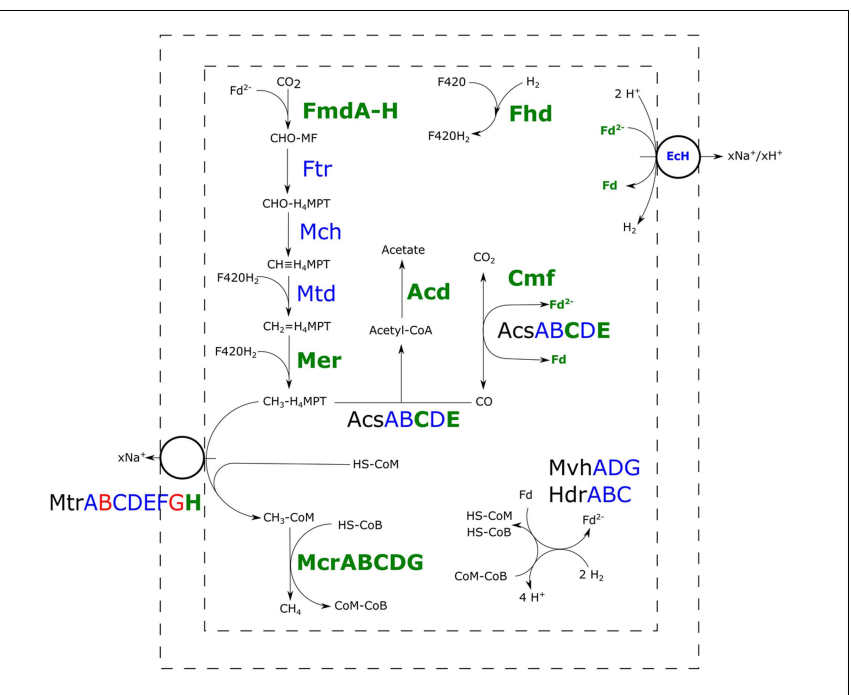

FIGURE 3 | Comparative proteomic analysis of methanogenic metabolism of $M$. marburgensis grown on $\mathrm{H}_{2} / \mathrm{CO}_{2} / \mathrm{CO}$ or $\mathrm{H}_{2} / \mathrm{CO}_{2}$. Relative abundance of proteins of carboxydotrophic growth compared to hydrogenotrophic growth is shown. Proteins highlighted green are found more abundantly present, proteins highlighted blue are not significantly changed in abundance and proteins highlighted in red are found to be less abundant in presence of $\mathrm{CO}(p<0.05)$. Fmd, formyl-methanofuran dehydrogenase; Ftr, tetramethanopterin formyl-transferase; Mch, methenyltetramethanopterin cyclohydrolase; Mtd, methylene- $\mathrm{H}_{4}$ MPT dehydrogenase; Mer, methylene- $\mathrm{H}_{4}$ MPT reductase; Acs, acetyl-CoA synthase; Acd, acetyl-CoA synthetase; $\mathrm{Cmf}, \mathrm{CODH}$ maturation factor; Mvh/Hdr, F420-non-reducing hydrogenase/heterodisulfide reductase; Mtr, tetrahydromethanopterin

$S$-methyltransferase; Mcr, methyl-coenzyme M reductase; $\mathrm{EcH}$, energy conserving hydrogenase; Fhd, F420 dehydrogenase; $\mathrm{H}_{4} \mathrm{MPT}$,

tetrahydromethanopterin; MF, methanofuran. tested here, and thus no conclusions can be drawn on its function. However, as the CO concentrations used in this study are relatively low, it is possible this protein is involved in COdetoxification at higher $\mathrm{CO}$ pressures, similar to the observation in $M$. acetivorans. However, a different role or non-functionality of this protein cannot be ruled out.

\section{Methyl-Branch Related Proteins}

In addition to $\mathrm{CODH} / \mathrm{ACS}$ related proteins, several enzymes involved in the methyl-branch of the reductive acetyl-CoA pathway were more abundant in cultures grown on $\mathrm{H}_{2} / \mathrm{CO}_{2} / \mathrm{CO}$. In particular, formylmethanofuran dehydrogenase, acting in the formation of formylmethanofuran from $\mathrm{CO}_{2}$, and the F420-dependent methylene- $\mathrm{H}_{4} \mathrm{MPT}$ dehydrogenase, involved in generation of methyl- $\mathrm{H}_{4} \mathrm{MPT}$ from methylene- $\mathrm{H}_{4} \mathrm{MPT}$, are significantly more abundant in incubations with CO (Table 1, Figure 3 ). Both proteins play a role in re-oxidation of co-factors, and their higher abundance might assist in countering the redox pressure of CO. Other proteins involved in the methyl-branch stay similar in abundance compared to incubations with $\mathrm{H}_{2} / \mathrm{CO}_{2}$ (Figure 3).

The higher abundance of several enzymes in the methylbranch in $\mathrm{H}_{2} / \mathrm{CO}_{2} / \mathrm{CO}$-grown $M$. marburgensis is expected to result in an increased flow through the pathway and thus requires up-regulation of subsequent pathways. This might explain the 'switching-on' of the acetate formation pathway and the increased production of enzymes involved in the final steps of methanogenesis (Figure 3). The observed acetate formation by $M$. marburgensis in presence of $\mathrm{CO}$ is supported by the finding of higher abundance of a predicted acetyl-coenzyme A synthetase (E.C. 6.2.1.1), theorized to be involved in acetate production and consumption. Proteomics data of $M$. marburgensis grown on $\mathrm{H}_{2} / \mathrm{CO}_{2} / \mathrm{CO}$ shows higher abundance of all subunits of methyl-coenzyme $M$ reductase. Additionally, the $\mathrm{H}$-subunit of tetrahydromethanopterin methyl-transferase is found to be more abundant. Studies on the H-subunit in M. thermoautotrophicus shows it catalyses the conversion of $\mathrm{cob}(\mathrm{I})$ alamin with $\mathrm{CH}_{3}$ $\mathrm{H}_{4} \mathrm{MPT}$ to methylcob(III)alamin, but lacks conversion activity of methylcob(III)alamin to methyl-CoM in absence of the rest of the complex (Hippler and Thauer, 1999). Other subunits of this complex are unchanged or even lowered in abundance in presence of $\mathrm{CO}$ (Figure 3). The membrane associated nature of this protein complex might have hindered accurate quantification, making it difficult to assess the relative abundance of the different subunits between the two conditions. This hinders the assessment of the role of the complex as a whole in the carboxydotrophic methanogenic metabolism of $M$. marburgensis.

Comparing the proteomics results obtained here with results reported for $M$. acetivorans is difficult as the native aceticlastic metabolism of $M$. acetivorans is different from the hydrogenotrophic metabolism of $M$. marburgensis. $M$. acetivorans cannot be grown on hydrogen and comparative proteomic studies with $\mathrm{CO}$ have been performed using acetate and methanol as alternative substrates (Lessner et al., 2006; Rother et al., 2007). A detailed comparison between the carboxydotrophic metabolism of $M$. acetivorans and M. marburgensis would therefore not be accurate.

\section{Limitations in Hydrogenotrophic Carboxydotrophic Methanogenic Metabolism}

Carbon monoxide affects metalloproteins by interacting with their active-centers via back-bonding (Jeoung et al., 2014). Hydrogenases are considered CO-sensitive enzymes and $\mathrm{H}_{2}$ metabolism of several microbial strains is inhibited by $\mathrm{CO}$ (Daniels et al., 1977; Genthner and Bryant, 1982; Bertsch and Müller, 2015). However, [Ni-Fe]-hydrogenases are considered more robust and more resistant to CO-inhibition (Adams, 1990; De Lacey et al., 2007). Hydrogenases involved in methanogenesis are in general $[\mathrm{Ni}-\mathrm{Fe}]$-hydrogenases, except for the iron-only hydrogenase present in $M$. thermoautotrophicus, replacing the methylene- $\mathrm{H}_{4} \mathrm{MPT}$ reductase in nickel deprived conditions (Afting et al., 1998, 2000). Higher CO-pressures seem to inhibit the metabolism of both $M$. thermoautotrophicus and M. marburgensis, as can be seen from the slowing down in $\mathrm{H}_{2}$ consumption rate. However, the ability of both strains to coutilize $\mathrm{H}_{2}$ and $\mathrm{CO}$ suggests hydrogenase inhibition is not the only mechanism of toxicity in these hydrogenotrophic methanogens.

Carbon monoxide has a low redox-potential $\left(E^{0 \prime}=-520 \mathrm{mV}\right)$, which can be seen as a major difficulty for the 
TABLE 1 | Highlighted set of more abundant proteins of $M$. marburgensis grown on $\mathrm{H}_{2} / \mathrm{CO}_{2} / \mathrm{CO} \mathrm{vs}$. $\mathrm{H}_{2} / \mathrm{CO}_{2}$.

\section{Protein}

\section{Methanogenesis related proteins}

Tungsten formylmethanofuran dehydrogenase (subunit A)

Tungsten formylmethanofuran dehydrogenase (subunit B)

Tungsten formylmethanofuran dehydrogenase (subunit C)

Tungsten formylmethanofuran dehydrogenase (subunit D)

Tungsten Formylmethanofuran dehydrogenase (subunit F)

Tungsten formylmethanofuran dehydrogenase (subunit G)

F420-dependent methylene-H4MPT dehydrogenase

Methyl-coenzyme $\mathrm{M}$ reductase component A2-like protein

Methyl-coenzyme $M$ reductase I subunit alpha

Methyl-coenzyme $\mathrm{M}$ reductase I subunit beta

Methyl-coenzyme $\mathrm{M}$ reductase I subunit gamma

Methyl-coenzyme $M$ reductase I operon protein $D$

Methyl-coenzyme $\mathrm{M}$ reductase I operon protein $\mathrm{C}$

Tetrahydromethanopterin S-methyltransferase subunit $\mathrm{H}$

\section{CODH/ACS related proteins}

Acetyl-CoA synthase, subunit gamma

Acetyl-CoA synthase, subunit epsilon

Carbon monoxide dehydrogenase, iron sulfur subunit

CO dehydrogenase maturation factor

Acetate related genes

Predicted acetyl-coenzyme A synthetase
Relative abundance $\left(\mathrm{H}_{2} / \mathrm{CO}_{2} / \mathrm{CO}\right.$ vs. $\left.\mathrm{H}_{2} / \mathrm{CO}_{2}\right)$

A cutoff value of $p<0.05$ was used to assess if proteins were more abundantly present. The complete proteomics dataset can be found in Supplementary Table S1.

methanogens. Generation of ferredoxin by hydrogenotrophic methanogens is in general done via reverse proton transport via the EcH or a bifurcation reaction performed by a F420non-reducing hydrogenase (Buckel and Thauer, 2013). The low redox potential of $\mathrm{CO}$ does, however, allow for direct reduction of ferredoxin via $\mathrm{CODH}$, making reduced ferredoxin more accessible in the cell. This lowers the $F d_{\mathrm{ox}} / F d_{\text {red }}$ ratio in the cell, lowering the electron potential of the ferredoxin couple. Judging from proteomics data, several redox response systems are activated. However, many of these, such as the superoxide dismutase and F420-oxidase, are normally a response to oxidized compounds (e.g., oxygen), which is the opposite of the more reduced environment created by $\mathrm{CO}$. It might be that these genes respond to redox stress in general or are regulated by universal stress proteins. Additionally, the F390-synthetase, involved in redox sensing was found to be more abundant. In $M$. thermoautotrophicus, this system was found to react on changes in redox potential, regulating the expression of MCR-I, F420-dependant $\mathrm{MDH}$, and the F420-reducing hydrogenase (Vermeij et al., 1997). The $\mathrm{CFE}$ of $\mathrm{H}_{2} / \mathrm{CO}_{2} / \mathrm{CO}$ grown cells showed more endogenous activity when compared to $\mathrm{H}_{2} / \mathrm{CO}_{2}$ grown cells. This could indicate more reducing equivalents are present in the cells grown in presence of CO. The overall increase in abundance of proteins involved in redox stress and co-factor regeneration, and the higher endogenous reducing activity suggest that $M$. marburgensis cells exposed to $\mathrm{CO}$ are subjected to changes in redox balance.

When grown solely on CO, M. marburgensis shows production of $\mathrm{H}_{2}$ from the moment incubation is started
(Figure 2). Methanogenesis is not started instantly, and CO appears to be solely used for $\mathrm{H}_{2}$ production. Methanogenesis initiates only after $\mathrm{H}_{2}$ has accumulated in the headspace (Figures 2 and 4) and, from that point on, quickly co-utilizing $\mathrm{H}_{2}$ and $\mathrm{CO}$. These data suggest that a minimal amount of $\mathrm{H}_{2}$ is required to operate the carboxydotrophic methanogenic metabolism. We theorize this is related to the properties of the bifurcating F420-non-reducing hydrogenase required to regenerate $\mathrm{CoM}-\mathrm{SH}$ and $\mathrm{CoB}-\mathrm{SH}$. Feasibility of the overall bifurcating reaction was estimated by calculating the potential difference between the two separate reactions catalyzed (Eqs 1 and 2). The following assumptions were made during calculation: (I) $\mathrm{pH}$ is assumed to be 7 and temperature $338 \mathrm{~K}$, (II) the ferredoxin couple is assumed to have a standard electron potential of $-500 \mathrm{mV}$ under physiological conditions (Thauer et al., 2008), but is assumed to approach the electron potential of the $\mathrm{CO} / \mathrm{CO}_{2}$ couple at the respective partial pressures (assessed via Nernst equation). Similarly the electron potential of $\mathrm{H}_{2}$ is assumed to be similar to its partial pressure, (III) the $\mathrm{CoM}-\mathrm{CoB}$ couple is assumed to have an electron potential of $-140 \mathrm{mV}$, and (IV) the bifurcation reaction is considered feasible if the sum in potential of reaction 1 and 2 has a negative value.

$$
\begin{array}{r}
\mathrm{H}_{2}+\mathrm{Fd} \rightarrow 2 \mathrm{H}^{+}+\mathrm{Fd}^{2-} \quad E^{0^{\prime}}=+86 \mathrm{mV} \\
\mathrm{CoM}-\mathrm{CoB}+\mathrm{H}_{2} \rightarrow \mathrm{CoM}-\mathrm{SH}+\mathrm{CoB}-\mathrm{SH} \\
E^{0^{\prime}}=-274 \mathrm{mV}
\end{array}
$$




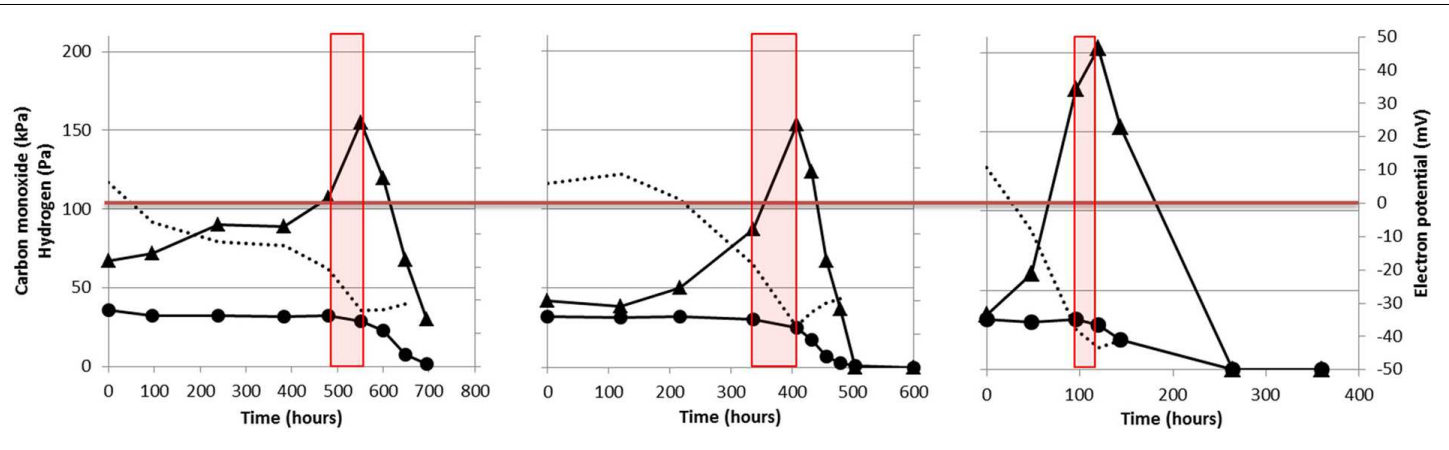

FIGURE 4 | Thermodynamic analysis of the reaction catalyzed by the F420-non-reducing hydrogenase in $\boldsymbol{M}$. marburgensis. The used dataset is the same as the one displayed in Figure 2. $\mathrm{H}_{2}$ pressure in $\mathrm{Pa}$ is given by the black triangles and the carbon monoxide pressure in $\mathrm{kPa}$ is given by the black circles. The estimated difference between the two reactions catalyzed by the bifurcating F420-non-reducing hydrogenase is indicated by the dotted black line. Red boxes indicate the phase where methanogenesis is initiated. The last time point is not assessed as the gasses had reached a pressure which could not be determined accurately.

$\mathrm{H}_{2}$ has to drive the reduction of both $\mathrm{CoM}-\mathrm{CoB}$ and ferredoxin in the reaction catalyzed by the F420-non-reducing hydrogenase. However, as the electron potential of ferredoxin is expected to be lowered in presence of $\mathrm{CO}$, and $\mathrm{H}_{2}$ is almost absent in the cultures, the overall reaction becomes less exergonic. When assessing the difference between the two separate reactions, it is observed that the overall reaction is not favored under the starting conditions of incubation (Figure 4, dotted lines). Under these conditions the CoM$\mathrm{SH}$ and $\mathrm{CoB}-\mathrm{SH}$ cannot be replenished, potentially blocking methanogenesis. As more $\mathrm{H}_{2}$ is generated, via the $\mathrm{EcH}$ complex, the reaction becomes more favorable, eventually allowing to start methanogenesis (Figure 4). Inhibition of hydrogenases or an irreversible reduced state of the cell at higher $\mathrm{CO}$ pressures could prevent $\mathrm{H}_{2}$ production and consumption, preventing the methanogenic metabolism from starting. The proposed limitation of the F420-non-reducing hydrogenase might explain why hydrogenotrophic methanogens as M. marburgensis and $M$. thermoautotrophicus can only utilize $\mathrm{CO}$ as a sole substrate up to $50 \mathrm{kPa}$, whereas $M$ barkeri and $M$. acetivorans, which do not employ a bifurcating F420-non-reducing hydrogenase (Thauer et al., 2008), can perform carboxydotrophic growth using $>100 \mathrm{kPa}$ and $>150 \mathrm{kPa} \mathrm{CO}$, respectively. The CO metabolism of hydrogenotrophic methanogens is thus potentially limited by their F420-non-reducing hydrogenase, and this would explain the observation that their efficiency of carboxydotrophic growth is strongly connected to the availability of hydrogen.

\section{CONCLUSION}

The hydrogenotrophic methanogen $M$. marburgensis, was found to grow methanogenically on $\mathrm{H}_{2} / \mathrm{CO}_{2} / \mathrm{CO}$ or $\mathrm{CO}$ alone. $\mathrm{CO}$ could be used as a sole substrate up to $50 \mathrm{kPa}$ and its consumption was stimulated in the presence of hydrogen. Proteomic analysis indicates higher abundance of CODH/ACS related proteins and enzymes of the methyl-branch in presence of CO. Most of the abundant proteins in cultures grown in the presence of $\mathrm{CO}$ are involved in redox reactions, potentially required to counter the strong reducing capacity of CO. Additionally, the pathway toward acetate production was found up-regulated, which explains formation of small amounts of acetate as an end-product in presence of $\mathrm{CO}$. The ability to utilize $\mathrm{H}_{2}$ in the presence of $\mathrm{CO}$ suggests that hydrogenase inhibition is not the main mechanism of toxicity in hydrogenotrophic methanogens. The requirement of small amounts of hydrogen, before methanogenesis with $\mathrm{CO}$ could start, suggests that this is an essential intermediate in the methanogenic metabolism. The F420-non-reducing bifurcating hydrogenase is a likely candidate for $\mathrm{CO}$ inhibition as low $\mathrm{H}_{2}$ pressures potentially can cause this reaction to become unfavorable, blocking the methanogenic metabolism.

\section{AUTHOR CONTRIBUTIONS}

MD: Experimental work, data analysis, drafting and writing manuscript. RP: Experimental work and data analysis. HW:Proteomics and data analysis. AS: Experimental design and critical revision of the manuscript. DS: Experimental design, data analysis, and writing the manuscript.

\section{ACKNOWLEDGMENTS}

Research of AS is supported by an ERC grant (project 323009) and a Gravitation grant (project 024.002.002) of the Netherlands Ministry of Education, Culture and Science and the Netherlands Science Foundation (NWO).

\section{SUPPLEMENTARY MATERIAL}

The Supplementary Material for this article can be found online at: http://journal.frontiersin.org/article/10.3389/fmicb.2016. 01049

TABLE S1 | Comparative proteomic analysis of $\mathrm{H}_{2} / \mathrm{CO}_{2}$ vs. $\mathrm{H}_{2} / \mathrm{CO}_{2} / \mathrm{CO}$ grown cells of Methanothermobacter marburgensis. 


\section{REFERENCES}

Abee, T., and Wouters, J. A. (1999). Microbial stress response in minimal processing. Int. J. Food Microbiol. 50, 65-91. doi: 10.1016/S0168-1605(99) 00078-1

Adams, M. W. (1990). The structure and mechanism of iron-hydrogenases. Biochim. Biophys. Acta 1020, 115-145. doi: 10.1016/0005-2728(90)90044-5

Afting, C., Hochheimer, A., and Thauer, R. (1998). Function of H2-forming methylenetetrahydromethanopterin dehydrogenase from Methanobacterium thermoautotrophicum in coenzyme F420 reduction with H2. Arch. Microbiol. 169, 206-210. doi: 10.1007/s002030050562

Afting, C., Kremmer, E., Brucker, C., Hochheimer, A., and Thauer, R. K. (2000). Regulation of the synthesis of $\mathrm{H} 2$-forming methylenetetrahydromethanopterin dehydrogenase (Hmd) and of HmdII and HmdIII in Methanothermobacter marburgensis. Arch. Microbiol. 174, 225-232. doi: 10.1007/s0020300 00197

Bertsch, J., and Müller, V. (2015). CO metabolism in the acetogen Acetobacterium woodii. Appl. Environ. Microbiol. 81, 5949-5956. doi: 10.1128/AEM. 01772-15

Bonam, D., and Ludden, P. (1987). Purification and characterization of carbon monoxide dehydrogenase, a nickel, zinc, iron-sulfur protein, from Rhodospirillum rubrum. J. Biol. Chem. 262, 2980-2987.

Bott, M., Eikmanns, B., and Thauer, R. K. (1986). Coupling of carbon monoxide oxidation to $\mathrm{CO} 2$ and $\mathrm{H} 2$ with the phosphorylation of ADP in acetate-grown Methanosarcina barkeri. Eur. J. Biochem. 159, 393-398. doi: 10.1111/j.14321033.1986.tb09881.x

Buckel, W., and Thauer, R. K. (2013). Energy conservation via electron bifurcating ferredoxin reduction and proton/ $\mathrm{Na}+$ translocating ferredoxin oxidation. Biochim. Biophys. Acta 1827, 94-113. doi: 10.1016/j.bbabio.2012. 07.002

Cox, J., and Mann, M. (2008). MaxQuant enables high peptide identification rates, individualized ppb-range mass accuracies and proteome-wide protein quantification. Nat. Biotechnol. 26, 1367-1372. doi: 10.1038/nbt. 1511

Daniell, J., Köpke, M., and Simpson, S. (2012). Commercial biomass syngas fermentation. Energies 5, 5372-5417. doi: 10.3390/ en5125372

Daniels, L., Fuchs, G., Thauer, R., and Zeikus, J. (1977). Carbon monoxide oxidation by methanogenic bacteria. J. Bacteriol. 132, 118-126.

De Lacey, A. L., Fernandez, V. M., Rousset, M., and Cammack, R. (2007). Activation and inactivation of hydrogenase function and the catalytic cycle: spectroelectrochemical studies. Chem. Rev. 107, 4304-4330. doi: $10.1021 / \mathrm{cr} 0501947$

De Mes, T., Stams, A., Reith, J., and Zeeman, G. (2003). "Methane production by anaerobic digestion of wastewater and solid wastes," in Biomethane and Biohydrogen. Status and Perspectives of Biological Methane and Hydrogen Production, eds J. H. Reith, R. H. Wijffels, and H. Barten (Petten: Dutch Biological Hydrogen Foundation), 58-102.

Diender, M., Stams, A. J., and Sousa, D. Z. (2015). Pathways and bioenergetics of anaerobic carbon monoxide fermentation. Front. Microbiol. 6:1275. doi: 10.3389/fmicb.2015.01275

Fischer, F., Lieske, R., and Winzer, K. (1931). Die umsetzungen des kohlenoxyds. Biochem. Z 236, 247-267.

Genthner, B. S., and Bryant, M. (1982). Growth of Eubacterium limosum with carbon monoxide as the energy source. Appl. Environ. Microbiol. 43, 70-74.

Hippler, B., and Thauer, R. K. (1999). The energy conserving methyltetrahydromethanopterin: coenzyme $\mathrm{M}$ methyltransferase complex from methanogenic archaea: function of the subunit MtrH. FEBS Lett. 449, 165-168. doi: 10.1016/S0014-5793(99)00429-9

Jeoung, J.-H., Fesseler, J., Goetzl, S., and Dobbek, H. (2014). "Carbon monoxide. toxic gas and fuel for anaerobes and aerobes: carbon monoxide dehydrogenases," in The Metal-Driven Biogeochemistry of Gaseous Compounds in the Environment, eds P. M. H. Kroneck and M. E. Sosa Torres (Dordrecht: Springer), 37-69.
Jönsson, L. J., and Martín, C. (2016). Pretreatment of lignocellulose: formation of inhibitory by-products and strategies for minimizing their effects. Bioresour. Technol. 199, 103-112. doi: 10.1016/j.biortech.2015.10.009

Lessner, D. J., Li, L., Li, Q., Rejtar, T., Andreev, V. P., Reichlen, M., et al. (2006). An unconventional pathway for reduction of $\mathrm{CO} 2$ to methane in $\mathrm{CO}$-grown Methanosarcina acetivorans revealed by proteomics. Proc. Natl. Acad. Sci. U.S.A. 103, 17921-17926. doi: 10.1073/pnas.0608833103

Liesegang, H., Kaster, A.-K., Wiezer, A., Goenrich, M., Wollherr, A., Seedorf, H., et al. (2010). Complete genome sequence of Methanothermobacter marburgensis, a methanoarchaeon model organism. J. Bacteriol. 192, 5850-5851. doi: 10.1128/JB.00844-10

Matschiavelli, N., Oelgeschlager, E., Cocchiararo, B., Finke, J., and Rother, M. (2012). Function and regulation of isoforms of carbon monoxide dehydrogenase/acetyl coenzyme A synthase in Methanosarcina acetivorans. J. Bacteriol. 194, 5377-5387. doi: 10.1128/JB.00881-12

O’Brien, J. M., Wolkin, R., Moench, T., Morgan, J., and Zeikus, J. (1984). Association of hydrogen metabolism with unitrophic or mixotrophic growth of Methanosarcina barkeri on carbon monoxide. J. Bacteriol. 158, 373-375.

Rother, M., and Metcalf, W. W. (2004). Anaerobic growth of Methanosarcina acetivorans $\mathrm{C} 2 \mathrm{~A}$ on carbon monoxide: an unusual way of life for a methanogenic archaeon. Proc. Natl. Acad. Sci. U.S.A. 101, 16929-16934. doi: 10.1073/pnas.0407486101

Rother, M., Oelgeschläger, E., and Metcalf, W. W. (2007). Genetic and proteomic analyses of CO utilization by Methanosarcina acetivorans. Arch. Microbiol. 188, 463-472. doi: 10.1007/s00203-007-0266-1

Techtmann, S. M., Lebedinsky, A. V., Colman, A. S., Sokolova, T. G., Woyke, T., Goodwin, L., et al. (2012). Evidence for horizontal gene transfer of anaerobic carbon monoxide dehydrogenases. Front. Microbiol. 3:132. doi: $10.3389 /$ fmicb. 2012.00132

Thauer, R. K., Kaster, A.-K., Seedorf, H., Buckel, W., and Hedderich, R. (2008). Methanogenic archaea: ecologically relevant differences in energy conservation. Nat. Rev. Microbiol. 6, 579-591. doi: 10.1038/nrmicro1931

van de Guchte, M., Serror, P., Chervaux, C., Smokvina, T., Ehrlich, S. D., and Maguin, E. (2002). Stress responses in lactic acid bacteria. Antonie Van Leeuwenhoek 82, 187-216. doi: 10.1023/A:1020631532202

Vermeij, P., Pennings, J., Maassen, S. M., Keltjens, J. T., and Vogels, G. D. (1997). Cellular levels of factor 390 and methanogenic enzymes during growth of Methanobacterium thermoautotrophicum deltaH. J. Bacteriol. 179, 6640-6648.

Vizcaíno, J. A., Csordas, A., Del-Toro, N., Dianes, J. A., Griss, J., Lavidas, I., et al. (2016). 2016 update of the PRIDE database and its related tools. Nucleic Acids Res. 44, D447-D456. doi: 10.1093/nar/gkv1145

Wagner, R. (1994). The regulation of ribosomal RNA synthesis and bacterial cell growth. Arch. Microbiol. 161, 100-109. doi: 10.1007/BF00276469

Wessels, H., Gloerich, J., Van Der Biezen, E., Jetten, M., and Kartal, B. (2010). Liquid chromatography-mass spectrometry-based proteomics of Nitrosomonas. Methods Enzymol. 486, 465-482. doi: 10.1016/B978-0-12381294-0.00021-3

Zhou, Y., Dorchak, A. E., and Ragsdale, S. W. (2013). In vivo activation of methyl-coenzyme M reductase by carbon monoxide. Front. Microbiol. 4:69. doi: $10.3389 /$ fmicb.2013.00069

Conflict of Interest Statement: The authors declare that the research was conducted in the absence of any commercial or financial relationships that could be construed as a potential conflict of interest.

Copyright (c) 2016 Diender, Pereira, Wessels, Stams and Sousa. This is an openaccess article distributed under the terms of the Creative Commons Attribution License (CC BY). The use, distribution or reproduction in other forums is permitted, provided the original author(s) or licensor are credited and that the original publication in this journal is cited, in accordance with accepted academic practice. No use, distribution or reproduction is permitted which does not comply with these terms. 